\title{
Practice and Research on the Reform of Teaching Methods in Circuit Course
}

\author{
Jianqin $\mathrm{Xu}^{*}$ \\ Engineering training center \\ Guangxi University of Science and Technology \\ Liuzhou, China \\ gxutxjq@126.com
}

\author{
Kene Li \\ School of Electrical and Information Engineering \\ Guangxi University of Science and Technology \\ Liuzhou, China \\ likene@163.com
}

\author{
Qifeng Liang \\ Engineering training center \\ Guangxi University of Science and Technology \\ Liuzhou, China
}

\begin{abstract}
The purpose of this article is to evaluate the effectiveness of the teaching methods reform for course "Circuit", which is a basic course for electronic and electrical majors in ordinary colleges and universities. In this article, we analyze the characteristics of the "Circuit" course and the learning situation of the students through different teaching methods; then conducts practice and research on the teaching methods reform. The implementation of the teaching methods is mainly based on lectures, supplemented by "mastery learning" and "combination of work and study projects". The examination results of students from two different classes under different teaching methods were compared. The results show that the reform of teaching methods apparently improves the students' understanding of "Circuit" course and effectively improves teachers' teaching quality.
\end{abstract}

Keywords—circuit; teaching reform; practice; research

\section{INTRODUCTION}

"Circuit Theory" is an important basic course for electrical and electronic information majors in colleges. Learning and research in the fields of electronics, automation, measurement, and computer science is all based on "Circuit Theory". It is necessary to the study of subsequent professional courses such as "Analog Electronic Technology" and "Digital Electronic Technology". It is the foundation for students to work on electricity related areas after graduation, and it is also the foundation for students to broaden their professional knowledge and innovation research [1]. However, "Circuit Theory" is abstract theoretical curriculum. Students will feel strenuous, and even lose interest in learning. In our observation in recent years, we found that the final exam questions are not very difficult, even simpler than the previous exams, but the students' test scores are still generally low, failing rates of $30 \%$ or more. The number of students to retake the course continues to increase. The problem was that because the study of "Circuit Theory" was not laid well, some students felt that they had difficulty in learning. This brought some pressure to both students and teachers. Therefore, considering the actual situation, we investigate the curriculum characteristics of the

Sponsor:A project of higher education undergraduate teaching reform in Guangxi in 2017, "Research on inquiry teaching mode of electronic technology course and cultivation of students' application ability "( item no: 2017 jgb 292 ).
"Circuit" and the situation of students in our colleges, analyze the problems, and use this as a basis to reform the teaching methods of the curriculum and carry out the practice. We hope to find some effective teaching methods that not only guarantee the quality of teaching, but also improve students' learning effect.

\section{Multi-Angle ANALYSis OF THE PROBLEM}

Through the observation of the classroom teaching situation and the communication between teachers and students, from the perspectives of the students themselves, teachers, and the characteristics of the curriculum, the authors analyze the factors affecting the teaching effects. The problems are roughly as follows.

1) With the popularization of higher education, the enrollment in universities has increased, resulting in uneven quality of students in the ordinary universities. Some students are lack of learning ability, and their ability to accept new knowledge is not satisfactory.

2) There are many courses for college students. At the same time, they also need to take various social activities, resulting in insufficient time and energy to think independently of the assignments. Many students rush to complete the assignments, even plagiarize. After the course is over, they realize that there is few they really learned and they have problems with the exam.

3) The teacher adopts a single instructional teaching method in class. There is not enough interaction between teachers and students in class, which makes some students easily distracted. Classroom enthusiasm is not high. The most important thing is that this kind of traditional teaching method is not inspiring to students' ability of self-learning.

4) Learning "Circuit Theory", students need to have certain higher mathematical knowledge, so "Circuit Theory" is generally set in the second semester for freshmen. But many students' learning methods and ways of thinking have not yet fully converted from the high school model. They have poor self-learning skills and cannot keep up with the progress of class. 
5) "Circuit" is rich in content with strong abstract theory. Students do not know the purposes, key points of each chapter. They have a vague concept on the theorems and laws that they have learned. They have not mastered what they learned. They do not use knowledge correctly to analyze the calculation circuit.

\section{Teaching Method Discussion}

With the continuous development of college education, there have been a variety of teaching methods, each with its own characteristics and advantages. For example, lecture-style teaching method focuses on teachers to teach. This method is more efficient and more commonly used in colleges and universities, but this teaching style is lack of communication between teachers and students; the classroom atmosphere is not active. Therefore, the use of lecture-style teaching alone cannot guarantee the quality of teaching. After the authors investigated teaching methods and consulted relevant education reform materials, combined the problems during the teaching of "Circuit" course, a new teaching method based on lectures has been explored, supplemented by the "combination of work and study projects" method [2-4] and the "mastery learning" method [5-6].

"Circuit" is a curriculum with abstract content, theoretical strength, and practical guidance. If only the teacher-centered teaching style is adopted in the classroom, students are passive to accept theoretical knowledge. To inspire students' enthusiasm to learn, it is important that students should build their own knowledge through teaching, learning, and working. Teaching, learning, and working should be integrated. Therefore, in the "Circuit" teaching process, we must also emphasize "working", and that is the students who are "working". "Integration of work and study projects" is precisely to combine theory with practice. In classroom teaching, the combination of work and study is to visualize and concretize abstract theoretical knowledge through experiments (or practices), so that students can not only deepen their understanding of theoretical knowledge; but also improve their practical ability. The projects are naturally related to knowledge, so that students can be more interested in, and solve problems in the project with knowledge from class, and students can understand and be more familiar with the learning purposes. "Mastery learning" is based on the idea of "all students can learn" and based on collective teaching (class teaching system), supplemented by frequent and timely feedbacks from students. The "mastery learning" pedagogy can be divided into three steps: First is to set unit learning objectives, second is to conduct unit tests, and third is to selfevaluate timely.

In the teaching process, these two methods are integrated into lecture-style teaching methods and form a diversified teaching model. To a certain extent, this reform helps solve the problems in the above-mentioned teaching.

\section{THE IMPLEMENTATION OF TEACHING METHODS}

\section{A. Combining multimedia, board writing, teaching and interaction}

Multimedia teaching is a teaching method popular in the information age. Multimedia courseware produces teaching materials with pictures and texts. It can display teaching content more vividly. It broadens students' horizons, effectively helps students understand course content [7]. In addition, the teacher can save time in class and increase the amount of teaching information by pre-producing courseware. The disadvantage of multimedia teaching is that the projection interface is limited, the slides are switched frequently, and the students tend to have short cuts while listening to lectures, and the teacher's lecturing becomes faster. Board writing is a traditional teaching method. The advantage of board writing is that the presented contents are easily changed and the retention time is longer. Teachers can control the speed of lectures so that students have enough time to think and take notes, which helps students think, understand, consolidate, and remember what they have learned. In "Circuit", there are many basic theorems, laws, and methods of analysis. There are also many related circuits, examples, and exercises. In order to enable students to grasp relevant knowledge points through examples, analyze complex circuits, the authors demonstrate and explain step by step in the form of board writing, so as to deepen the students' understanding of knowledge points, and at the same time increase the interaction between teachers and students; and students can keep up with the speed of the class. Therefore, according to the actual situation, the authors combine the multimedia and the board writing while teaching, which complements each other and reduces disadvantages of each other.

\section{B. Incorporating the "mastery learning" to improve teaching quality}

According to the systematic characteristics of "mastery learning" method, the authors first divide the teaching contents into three teaching units according to the characteristics of various chapters of "Circuit": DC circuit part, AC circuit part, and transient response of the circuit; then proceed with the "mastery learning” method step by step.

The first step: setting unit learning objectives. At the beginning of each chapter, teachers will point out the learning content and explain the "learning goals" required to achieve. For example, the teaching objectives of the chapter "Circuit Model and Circuit Law" are as follows: (1) Understand circuit model, understand voltage, current reference direction, meaning of electric power and rated value; (2) Master the voltage-current relationship of ideal circuit components; (3) Master Kirchhoff's law and master the concept and calculation of potential. These hierarchically listed teaching objectives will make it clear to students how to master the contents of this chapter. In their learning process, they can also grasp the key points and improve learning efficiency.

The second step: Conducting unit tests. In order to enable students to understand their existing problems, but also enable teachers to get feedback from students, quiz questions are compiled according to the learning objectives, and various 
types of questions are used to assess how students have learned. For example, the key content to be evaluated by the DC circuit unit is: Kirchhoff's law, equivalent transformation of power supply, one-port input resistance, loop current method, nodal voltage method, superposition theorem, equivalent power theorem and maximum power transmission law. The contents of this unit are numerous, so the author follows the progress of teaching and conducts the quizzes twice. For the quizzes, students are required to complete independently without open book, so the students can clearly understand what they learned.

The third step: timely self-evaluation and tutorial assistance. After class, teachers try their best to evaluate each student's test sheet, analyze the student's mistakes and cause of error, understand the students' strength and weakness, and make more accurate assessment of the degree of student's mastery of learning. Return students' test sheet in the next class, explain answers, analyze the problem-solving ideas and steps of each topic in detail, and highlight errors easy to appear and contents not well-understood. Students can also make self-evaluations; keep abreast of their own knowledge and existing problems.

Through the implementation of the "mastery learning" approach, it effectively helps freshmen change their learning methods and thinking patterns. After the three teaching sessions, most students can meet the requirements of the set learning goals. Through the feedback of the tests, teachers and students can find problems timely, and master the content of each unit. At the same time, it helps broaden students' problemsolving ability such as flexibly applying different analytical methods and theorems to solve problems.

\section{Combination of work and study projects}

Teachers collect and sort out the circuit problems from actual daily electricity use related to the curriculum through information media or scientific research; and use these issues to guide students to think and discuss, so that students can actively participate in the classroom. This method can help students improve thinking ability, inspire enthusiasm and professionalism. The "traditional fluorescent lamp circuit" in our daily life is a good example when studying the chapter "Sinusoidal Steady Circuit". The authors first briefly introduce the structural principles of the fluorescent lamp and the starter, and then ask the students to think in turn about some simple issues, such as: (1) The role played by the ballast and the starter in the fluorescent lamp circuit; (2) If the starter is broken, what is the simplest way to make the lamp light up; (3) What is the role of the capacitor? Can you connect capacitors in series? After thinking about these questions, students can better understand the working principle of circuit devices, the nature of large voltages caused by abrupt changes in the current of inductive components, and the abstract knowledge points that shunt capacitors can increase the power factor of inductive circuits without affecting the working conditions of the load.

After basic lecture is explained, corresponding experimental projects are introduced. Through the guidance of theoretical knowledge, teachers can help students solve the problems encountered during the experimental projects; and strengthen students' practical ability to use theoretical knowledge. For example, the "Fluorescent Lamp Circuit" is selected as an experimental project. Through experiments, students can grasp the wiring of the fluorescent lamp circuit; access the AC voltmeter, ammeter, and power meter to observe the working conditions of the fluorescent lamp; incorporate in the capacitor $\mathrm{C}$, measurement of power factor; understand methods to improve the power factor of the circuit, changes in the nature of the circuit, replacement of the starter with a switch to light the fluorescent lamp, etc. During the implementation of the project, students become familiar with the use of equipment.

In practical teaching, students become the main body; constructing knowledge through "working" can inspire students' interest and enthusiasm for learning. Teachers guide and assist appropriately when they are needed.

In addition to such practical activities, students can also participate in interesting projects, according to the task of the project to seek knowledge; enhance their ability to analyze and solve problems; improve their professional knowledge.

\section{Teaching EfFect Analysis}

In order to evaluate the effectiveness of the teaching methods discussed in this paper, the authors chose students who entered college in 2014 of measurement and control major as the observing object of the teaching of "Circuit Theory A1", and carried out practical research work on teaching methods. After the observation of a whole semester, statistical analysis was performed on the final exams of the "Circuit Theory A1" and "Circuit Experiment", which was compared with the exam results of the same courses for students who entered college in 2011 of automation major. Students 2011 do not apply with the reform of the teaching methods. The statistical comparison results are as follows.

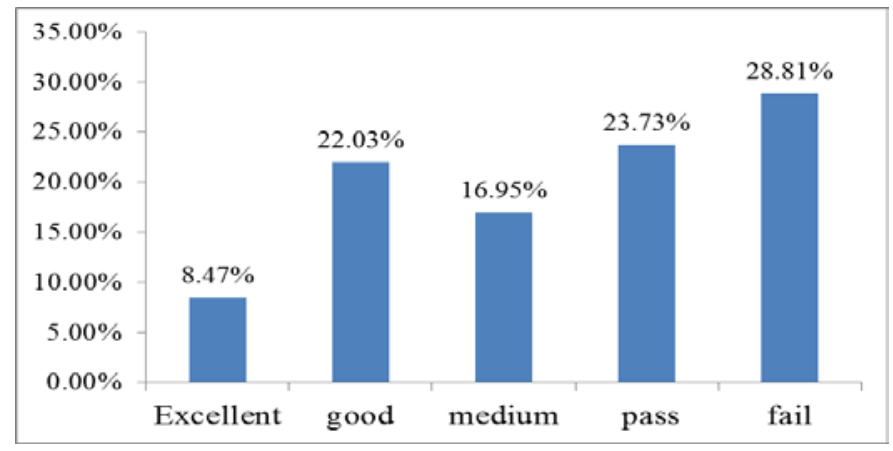

Fig. 1. Distribution of total scores of students 2011 "Circuit Theory A1"

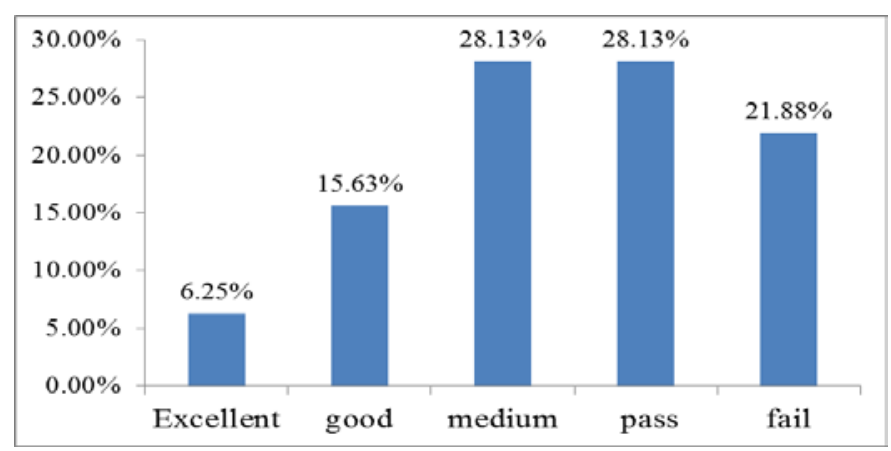

Fig. 2. Distribution of total scores of students 2014 "Circuit Theory A1" 
There are 59 students (2011) who actually participated in the "Circuit Theory A1" course examination and their total scores are shown in Fig. 1. There were 64 students (2014) who actually participated in the "Circuit Theory A1" course examination. Fig. 2 shows the distribution of the total scores of students (2014) "Circuit Theory A1". From the two distribution charts, we can see that the percentage of people with good and excellent results of the students (2011) is slightly higher; but the proportion of the students (2014) with a higher percentage of passing rate, about $7 \%$ higher.

Next, compare the examination results of the "Circuit Experiment" in these two classes. Fig. 3 shows the distribution of the total scores of the "Circuit Experiment" of the students (2011). Fig. 4 shows the distribution of the total scores of students (2014). Obviously, the overall situation of the "Circuit Experiment" assessment of the students (2014) is better than the students (2011).

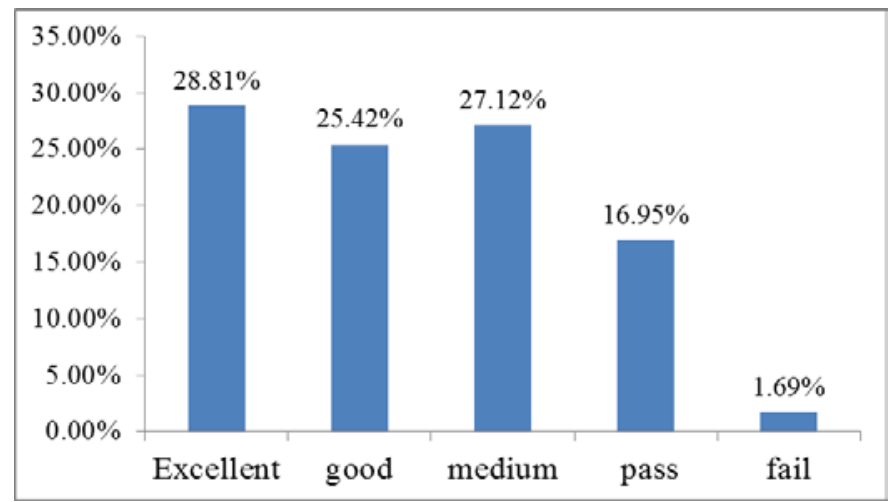

Fig. 3. Distribution of total scores of students 2011 "Circuit Experiment"

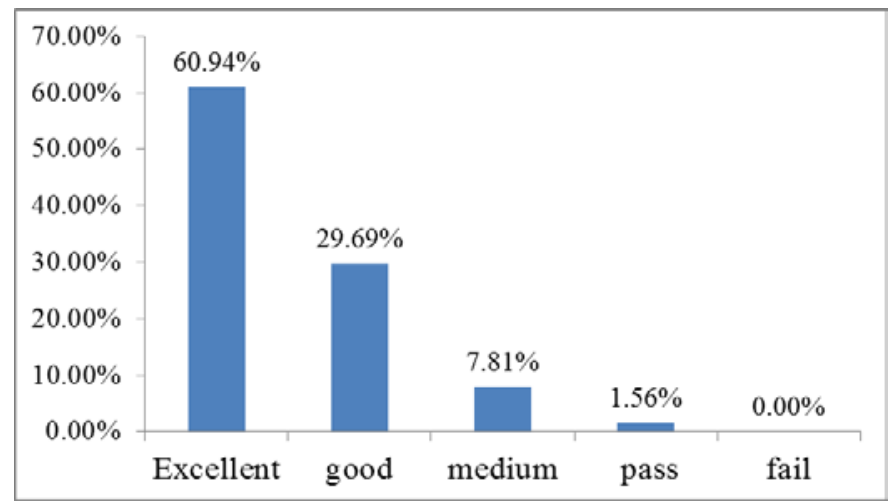

Fig. 4. Distribution of total scores of students 2014 "Circuit Experiments”

According to the comparison of the "Circuit Theory A1" and "Circuit Experiment" examinations, since the teaching of students (2014) is integrated the new teaching methods with the traditional teaching methods, we can see that the passing rate of class exams has improved, and most students can master the basic knowledge points required. Throughout the semester, the authors also noticed that the adoption of the new teaching methods could motivate students' initiative and enthusiasm for learning, arouse their attention to class, increase interaction with teachers in the classroom; and students seriously participated in the experiment. The results from the students' final exams and the classroom performance demonstrated that the teaching methods adopted in this "Circuit" course have achieved certain results. However, there are still a few students who failed to learn the key points of knowledge and meet the requirements of the course. Therefore, the teaching plan needs to be constantly optimized and the teaching quality needs to be continuously improved.

\section{SUMMARY}

On the basis of instructional teaching strategies, the teaching methods of "Mastery Learning" and "Combination of work and study projects" are introduced. To a certain extent, students' theoretical and practical abilities can be effectively improved, students' academic performance can be improved, and the quality of course teaching can be improved. We hope that we can continue to practice and observe this teaching model, persist in summing up and improving, and form a set of effective teaching methods, not only for the "Circuit" curriculum reform, but also a new idea for the teaching of other similar courses.

\section{REFERENCES}

[1] Guanyuan Qiu, Xianjue Luo, “Circuit,” (fifth edition). Higher Education Press, May 2006, In Chinese.

[2] Longgui Cheng, "How to teach circuit course," China Education Duide, No.11, pp.59-61, 2008, In Chinese.

[3] Zhenxing $\mathrm{Li}$, Zhenhua $\mathrm{Li}$, Yanchun $\mathrm{Xu}$, "Project-driven method in the circuit course teaching application and practice.” Education Teaching Forum, No.16, pp.136-137, April 2016, In Chinese.

[4] Xiaomin Yang. "Research and practice of curriculum reform of circuit and analog electronic technology.” Computer Era, No.9, pp.50-51, 2013, in Chinese.

[5] Ziming Yang, "An initial attempt of circuit course in education reform”. Chemical Production and Technology, No.3, pp.54-56, 1994, In Chinese.

[6] Tianmei Wu. "Bloom's mastery learning theory and foreign language teaching”. New Curriculum Research (Pentecost), No.1, pp.50-51, 2012, In Chinese.

[7] Kene $\mathrm{Li}$, Jianqin $\mathrm{Xu}$, “Electrical and electronic technology Course Teaching Reform Exploration.” Education Teaching Forum, No.23, pp.88-89, June 2015, in Chinese. 